\title{
Blue grama-buffalograss responses to grazing: A Weibull distribution
}

\author{
KIMBERLY K. REMINGTON, CHARLES D. BONHAM, AND ROBIN M. REICH
}

\author{
Authors are graduate research assistant and professar, Range Science Department, and associate professor, Forest \\ Science Department, Colorado State University, Fort Collins 80523.
}

\begin{abstract}
Characterization of standing herbaceous biomass on rangeland is complicated by both temporal and spatial variability that results from patchiness in vegetation. These patches often cause nonuniform levels of grazing by livestock. Currently accepted methods for estimation of forage, and its utilization, assume a normal distribution. This assumption may not be appropriate if the frequency distribution of amount of biomass becomes skewed as grazing occurs. We evaluated the 3 parameter Weibull distribution as an alternative to the normal distribution in modeling the frequency distributions of plant height and biomass as a function of grazing intensity over time in a shortgrass steppe. Weibull distributions, estimated by probability weighted moments, fit all observed plant height and biomass data distributions at the $\alpha=0.05$ level of significance. In contrast, the normal distribution fit only $25 \%$ of the data sets.
\end{abstract}

Key Words: Weibull distribution, normal distribution, shortgrass steppe, cattle grazing patterns

Rangelands occupy over $50 \%$ of the world's land and a measure of aboveground biomass of vegetation, especially forage, is needed for their management (Anderson and Currier 1973). These lands provide half of the feed needed for all domestic ruminants (Holechek et al. 1989). Therefore, measurement and monitoring of herbage biomass are needed because both are used to estimate stocking rate and the subsequent use of forage.

Forage utilization problems commonly result from grazing distribution of animals within pastures or grazing units. In particular, variance in topography, microclimate, location of fences along with location of salt and water, types of animals present, and shade locations influence in patterns of use by large herbivores (Williams 1954). As a result of these effects, forage on particular areas within a pasture may remain unused, while other areas may be overused.

Differential use by animals contributes to an uneven distribution of herbage that is arranged into complex mosaic spatial patterns (Shiyomi et al. 1984). Furthermore, this heterogeneity of herbage biomass varies with grazing intensity. That is, as a pasture is grazed more intensely, the spatial pattern of herbage biomass becomes more heterogeneous with pastures (Shiyomi et al. 1984).

Patterns of individual species and species combinations are not usually considered in a statistical analysis of plant biomass data. Yet, spatial patterns affect biomass estimates and commonly used statistics do not account for these patterns. Current range forage inventories assume a normal distribution of biomass and associated plant heights. The latter measure is often used to estimate utilization and plant vigor. However, Shiyomi et al. (1983, 1984,

Research was funded by the Colorado State University Agricultural Experiment Station, Project No. 156602(4242). Authors recognize Dr. James Forwood (now deceased), Agricultural Research Service, for his cooperation with the study site. The CPER is administered by the USDA-ARS.

Manuscript accepted 4 September 1991.
1985) have observed that the frequency distribution of biomass is not normally distributed, but rather, is more often skewed to the right. Thus, estimates of forage biomass distribution may be biased if obtained from the normal distribution. Therefore, an unbiased method is needed to account for heterogeneity of vegetation biomass when skewness occurs in the data.

The Weibull distribution which is named after Waloddi Weibull, a Swedish physicist, was originally developed in 1939 (Johnson and Kotz 1971). This distribution has been used to study disease progression, seed germination, fire interval prediction, and diameter distribution of forest stands (Wang and Lin 1986, Bridges et al. 1989, Baker 1989, Reich et al. unpublished).

The purpose of this study was to evaluate the feasibility of using a Weibull distribution to model the frequency distribution of plant heights and biomass of blue grama [Bouteloua gracilis (H.B.K.) Lagg. ex Steud] and buffalograss [Buchloe dactyloides (Nutt.) Engelm] on a shortgrass steppe site subjected to different levels of grazing. Our hypothesis was that plant heights and biomass follow a Weibull distribution.

\section{Methods}

The study was conducted on the Central Plains Experimental Range (CPER), located $61 \mathrm{~km}$ northeast of Fort Collins, Colorado. The climate is semiarid, with average annual precipitation of $310 \mathrm{~mm}$, of which $75 \%$ falls as rain throughout the growing season, April to October (Jameson et al. 1969). The topography is relatively flat with rolling hills that have an average elevation of 1,650 $\mathrm{m}$. Mean monthly temperatures range from $-5^{\circ} \mathrm{C}$ in January to $22^{\circ} \mathrm{C}$ in July.

Two 130-ha enclosed pastures, that have been grazed for about 30 years with yearling heifers and steers, were used in this study. One pasture was lightly grazed, while the other was heavily grazed. The Agriculture Research Service (ARS) maintains grazing treatments with the objective of leaving $452 \mathrm{~kg}$ forage $\mathrm{ha}^{-1}$ on the lightly grazed pasture and $226 \mathrm{~kg}$ forage $\mathrm{e}^{-1}$ on the heavily grazed pasture at the end of the season. Initial stocking rates from 24 May were 76 AUM $130 \mathrm{ha}^{-1}$ for the heavy and 40 AUM $130 \mathrm{ha}^{-1}$ for the light; in late October the rates were reduced to $13 \mathrm{AUM} 130 \mathrm{ha}^{-1}$ and 7 AUM $130 \mathrm{ha}^{-1}$, respectively, to meet ARS objectives.

Field data were collected during late May and June, midAugust, and in late October 1990. Blue grama and buffalograss biomass was considered as a single unit because of problems in separating the material into individual species. A double sampling technique, with a randomly placed $0.25-\mathrm{m}^{2}$ circular plot, was used to estimate standing biomass. A ratio of 3:1, between ocularly estimated plots and clipped plots, was used for data collection. Within each pasture 60 plots were estimated and 20 of these wcre randomly clipped at each time of sampling. Samples were ovendried at $60^{\circ} \mathrm{C}$ for 48 hours to a constant weight, and dry weights were recorded. The estimates were corrected using regression. Also, within each plot the tallest part of a plant was measured. 


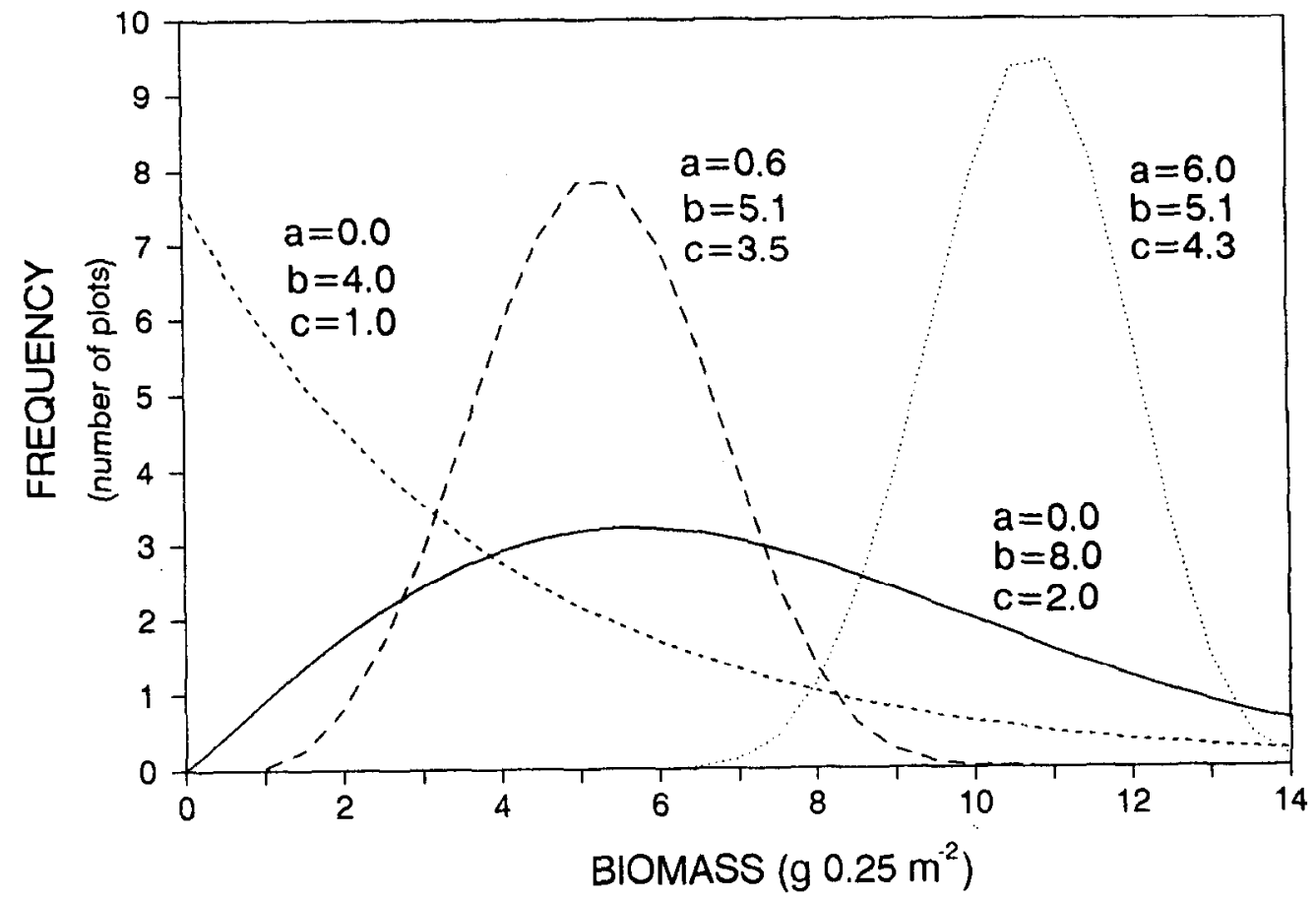

Fig. 1. Examples of Weibull distributions for illustrative values of parameters $(a, b, c)$.

\section{Statistical Analysis}

A Weibull distribution is expressed as:

$$
f(x ; a, b, c)=\left(\frac{c}{b}\right)\left(\frac{x-a}{b}\right)^{c-1} \operatorname{EXP}\left[-\left(\frac{x-a}{b}\right)^{c}\right]
$$

The $a$ parameter is the Weibull distribution location factor which corresponds to the smallest data value obtained; in the present case, $a$ was the smallest amount of biomass or the shortest maximum height of a blue grama or buffalograss plant. The $b$ parameter is called the scaling factor, which is a measure of the variability in the data set. The $c$ parameter measures the shape of the frequency distribution and determines the skewness and other shape properties of the distribution.

When the shape, $c$ parameter, is equal to 1.0 , the Weibull function reduces to an exponential distribution (Fig. 1). When $c$ is greater than 1, the Weibull distribution becomes mound shaped and skewed to the right. As $c$ approaches 3.5, the Weibull resembles a normal distribution. Finally, when $c$ becomes greater than 3.5 , the Weibull function is skewed to the left (Bailey and Dell 1973).

The frequency distributions of plant height and biomass were fitted to the 3 parameter Weibull distribution using probability weighted moments (PWM) (Grender et al. 1990). This procedure yields unbiased estimates of these parameters (Greenwood et al. 1979). Kolmogorov goodness-of-fit was determined for data fit, both to the Weibull and to the normal distribution (Hollander and Wolfe 1973, Stephens 1974). The level of significance used was $\alpha=$ 0.05 .

\section{Results and Discussion}

\section{Plant Heights}

Mean heights ranged from $6.0 \mathrm{~cm}$ in May to $18.4 \mathrm{~cm}$ during August in the lightly grazed pasture. This range is in contrast to mean plant heights of $5.1 \mathrm{~cm}$ in May to $14.2 \mathrm{~cm}$ in August, in the heavily grazed pasture. The greatest variability in plant heights was observed in August for both pastures. As expected, the larger variability in maximum plant heights occurred in the heavily grazed pasture, while the least variability was observed in the lightly grazed pasture during May.

These results indicated that plant heights increased from May to August for both treatments and then declined by October. This height increase suggested an active growing season for the 2 grasses, from May to August, followed by a decline as a result of senescence and prolonged grazing.

\section{Biomass}

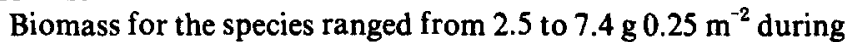
May and June, respectively, in the lightly grazed pasture. This is in contrast to the heavily grazed pasture, where biomass ranged from

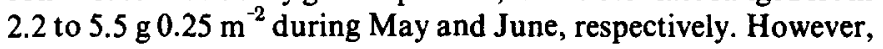
biomass results also indicated, as expected, that the least amount occurred in May, but increased until August for both levels of grazing and then declined over the next 2 sample dates. These results are similar to those found in previous studies of these species using comparable grazing levels (Milchunas et al. 1989, Milchunas et al. 1990).

Variability of observed biomass was greater in the heavily grazed pasture during June, while the least variability was observed in the heavily grazed pasture during May.

\section{Normal Distribution}

Based on Kolmogorov goodness-of-fit test, maximum plant heights were not normally distributed for any of the sampling dates in either the lightly or heavily grazed pasture (Table 1). But rather, maximum plant heights observed in our study, were skewed to the right $(c<3.5)$.

Biomass in the lightly grazed pasture was shown by the Kolmogorov goodness-of-fit tests to be approximately normally distributed for each sample date $(p \geq 0.05)$. This is in contrast to the distribution of forage biomass in the heavily grazed pasture; it was not normally distributed. Interpretation of the field data, for height and biomass indicates that these plant measures in the heavily grazed pasture were not normally distributed at any of the sample dates.

This lack-of-fit for biomass, using the normal distribution, 
Table 1. Comparison of the number of distributions using the normal and Weibull distribution for 16 data sets (4 dates, 2 levels and 2 variables). Kolmogorov goodness-of-fit test for each distribution $(p \geq 0.05)$.

\begin{tabular}{lcc}
\hline \hline & Normal & Weibull \\
\hline Lightly-grazed & 0 & 4 \\
Height & 4 & 4 \\
Biomass & & \\
Heavily-grazed & 0 & 4 \\
Height & 0 & 4 \\
Biomass & 4 & 16 \\
Total Fit & & \\
\hline
\end{tabular}

clearly demonstrates what Shiyomi (1983) describes as patterns caused by different levels of grazing over time. That is, as the intensity of grazing increases, the frequency distribution for biomass becomes skewed and no longer follows a normal distribution.

\section{Weibull Distribution}

The Weibull distribution was used as an alternative to the assumption of normality. Estimators of the Weibull parameters are given in Table 2 . The location parameter for heights, $a$, ranged

Table 2. Weibull parameters for plant heights (cm) and biomass (g 0.25 $\mathrm{m}^{-2}$ ) for grazing levels and dates.1

\begin{tabular}{llccc}
\hline \hline \multicolumn{1}{c}{ Month } & Location & Scale & Shape \\
\hline Height $(\mathrm{cm})$ & & & & \\
& May & 1.23 & 5.34 & 3.03 \\
& June & 4.29 & 11.29 & 1.14 \\
August & 0.0 & 20.79 & 2.10 \\
October & 0.0 & 14.65 & 2.27
\end{tabular}

Biomass

$\left(\mathrm{g} \bullet 25 \mathrm{~m}^{-2}\right)$

$\begin{array}{llll}\text { May } & 0.0 & 2.82 & 2.29 \\ \text { June } & 0.0 & 8.31 & 2.08 \\ \text { August } & 0.0 & 5.93 & 2.27 \\ \text { October } & 0.0 & 4.82 & 2.20\end{array}$

Height (cm)

$\begin{array}{llrl}\text { May } & 0.0 & 5.70 & 2.77 \\ \text { June } & 0.0 & 10.04 & 1.38 \\ \text { August } & 0.0 & 15.93 & 1.83 \\ \text { October } & 0.0 & 12.17 & 2.24\end{array}$

Biomass

$\left(\mathrm{g} \bullet 25 \mathrm{~m}^{-2}\right)$

\begin{tabular}{llll} 
May & 0.0 & 2.45 & 2.41 \\
June & 0.0 & 6.14 & 1.55 \\
August & 0.0 & 4.56 & 1.67 \\
October & 0.0 & 4.64 & 2.04 \\
\hline
\end{tabular}

'Location and scale parameters units correspond to those of plant heights and biomass; shape is unitless.

from 0.0 in August and October to $4.29 \mathrm{~cm}$ in June in the lightly grazed pasture. This range indicates that maximum height of all plants was at least $4.29 \mathrm{~cm}$ during June while for 2 sampling dates, August and October, the least, or shortest possible maximum height was 0.0 ; in other words, no plant was present in the plot. The $a$-parameter for heights in the heavily grazed pasture was 0.0 for all dates. This illustrates that at least 1 plot did not contain blue grama or buffalograss. In addition, we believe that as cattle grazed, the maximum plant height in a plot approached 0.0 over time.

The scale parameter, $b$, in the heavily grazed pasture ranged from 5.70 to $15.93 \mathrm{~cm}$ during May and August, respectively. In the lightly grazed pasture, also during May and August, plant heights ranged from 5.34 to $20.79 \mathrm{~cm}$, respectively. There was more variability in plant heights during August and the least amount during May. Plant heights peaked in August, but not uniformly in either pasture.

The scale parameter for biomass in the heavily grazed pasture ranged from 2.45 to $6.14 \mathrm{~g} 0.25 \mathrm{~m}^{-2}$ during May and June, respectively. In the lightly grazed pasture, biomass ranged from 2.82 to

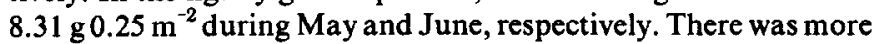
variability in biomass during June and the least variability in May. As precipitation occurred in early June, plant growth was accelerated, but not in a uniform fashion across the pasture.

The shape parameter $c$, as previously noted, determines the shape of the distribution. This parameter in the heavily grazed pasture for plant heights ranged from 1.14 in June to 3.03 in May. The $c$ parameter in the lightly grazed pasture ranged from 1.38 in June to 2.77 in May. Biomass in the heavily grazed pasture, for the shape parameter, ranged from 1.55 in June to 2.41 in May. This parameter in the lightly grazed pasture for biomass ranged from 2.08 in June to 2.29 in May. This range for the lightly grazed pasture indicates skewness to the right, but as previously noted, biomass was normally distributed. However, the skewness was not drastic enough to reject normality $(\alpha=0.05)$. This pasture illustrates that biomass was not significantly $(p<0.05)$ different from a normal distribution by the Kolmogorov goodness-of-fit test.

The $c$ parameter for both dates and both levels of grazing indicate skewness to the right. In turn, we believe that nonuniform grazing occurred over the season, which resulted in patches with different amounts in plant heights and biomass.

\section{Comparison of the Normal Versus the Weibull}

The statistical properties of selected percentiles were evaluated

Table 3. Relative error associated with percentiles calculated from Weibull distributions and normal distributions for plant heights and biomass during June for the heavily grazed pastures. ${ }^{1}$

\begin{tabular}{|c|c|c|c|}
\hline $\mathbf{k}^{2}$ & $F(x)=k / 30$ & Height & Biomass \\
\hline 2 & 0.03 & -6.56 & -2.93 \\
\hline 4 & 0.07 & -1.31 & -0.09 \\
\hline 6 & 0.10 & -3.10 & -0.57 \\
\hline 8 & 0.13 & -1.69 & -0.48 \\
\hline 10 & 0.17 & -0.87 & 5.15 \\
\hline 12 & 0.20 & 0.29 & -1.01 \\
\hline 14 & 0.23 & 1.46 & -3.17 \\
\hline 16 & 0.27 & 1.04 & 3.93 \\
\hline 18 & 0.30 & -1.47 & 31.80 \\
\hline 20 & 0.33 & -1.08 & -0.10 \\
\hline 22 & 0.37 & -2.28 & -1.29 \\
\hline 24 & 0.40 & -0.92 & -1.58 \\
\hline 26 & 0.43 & -1.46 & -1.59 \\
\hline 28 & 0.47 & -2.29 & -1.32 \\
\hline 30 & 0.50 & -2.37 & -1.94 \\
\hline 32 & 0.53 & -3.92 & -0.76 \\
\hline 34 & 0.57 & -7.13 & -1.31 \\
\hline 36 & 0.60 & -12.04 & -1.05 \\
\hline 38 & 0.63 & -278.17 & -1.89 \\
\hline 40 & 0.67 & 19.25 & -3.61 \\
\hline 42 & 0.70 & 8.33 & -4.24 \\
\hline 44 & 0.73 & -14.44 & -12.54 \\
\hline 46 & 0.77 & -73.92 & -3.01 \\
\hline 48 & 0.80 & 35.04 & -3.41 \\
\hline 50 & 0.83 & 2.13 & -3.69 \\
\hline 52 & 0.87 & -1.74 & -14.31 \\
\hline 54 & 0.90 & -0.23 & 15.75 \\
\hline 56 & 0.93 & -8.52 & 1.89 \\
\hline 58 & 0.97 & -2.75 & -27.09 \\
\hline
\end{tabular}

'Relative error $=\%$ error normal $/ \%$ error Weibull.

${ }^{2}$ Only even plot numbers are presented in ascending order of data values. 


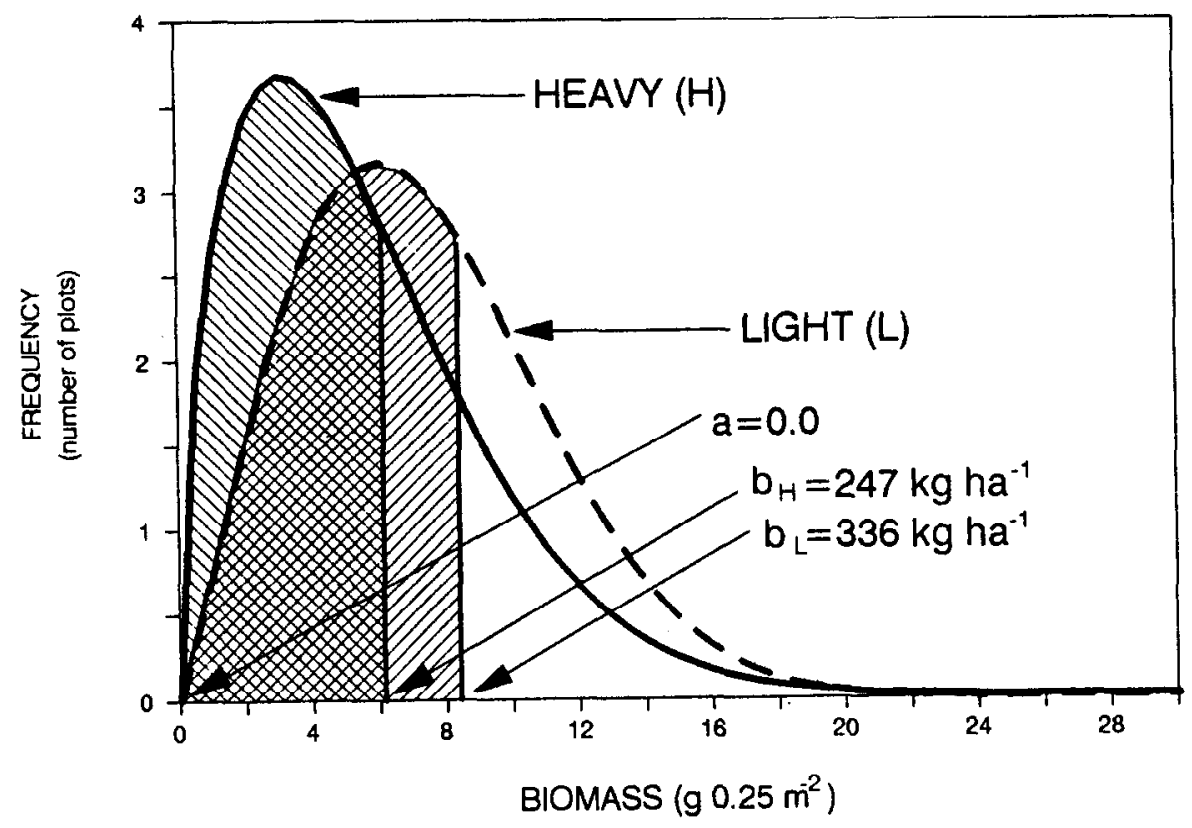

Fig. 2. Biomass of blue grama and buffalograss in the lightly and heavily grazed pastures during June based on a Weibull distribution.

to determine how well the normal and Weibull distribution described the observed data. A few representative results, presented in terms of the relative error associated with estimations of various percentiles are given in Table 3 . The relative error is equal to the percent error of the normal divided by the percent error of the Weibull. An absolute relative error greater than 1 indicated that the Weibull distribution provided a closer approximation of the sample data than the normal distribution.

The relative error for plant height at the 63 percentile $(F(x)=0.63)$ resulted in a large value of -278.17 . This extreme value resulted from the Weibull's expected value being only 0.01 units from the observed (actual) value. In 49 out of 58 percentiles selected over the range of the data, the Weibull described the data better than did the normal. Therefore, we conclude that the Weibull should be used instead of the normal when describing the distribution of plant heights and biomass in both lightly and heavily grazed pastures.

\section{Application}

As an example of the usefulness of the Weibull, forage biomass was estimated in the lightly and heavily grazed pastures during June. The $63 \%$ of the data values occurs when the location parameter $(a)$ is added to the scale parameter $(b)$ of the Weibull distribution (see Table 2 for $a+b=0.0+8.31$ for lightly grazed and $0.0+$ 6.14 for heavily grazed). This sum approximates the amount of forage biomass, such that $63 \%$ of the pasture has less than that amount of forage. This forage estimate is then easily converted by simple linear transformation into kilogram per hectare of dry weight.

Figure 2 depicts the estimated $63 \%$ in heavily and lightly grazed pasture for biomass during June. That is, $63 \%$ of the pasture area is estimated to have biomass ranging from 0.0 to $247 \mathrm{~kg} \mathrm{ha}^{-1}$, for the heavily grazed pasture and from 0.0 to $336 \mathrm{~kg} \mathrm{ha}^{-1}$ in the lightly grazed pastures. Consequently, $37 \%$ of the pasture was estimated to have biomass exceeding these values, respectively. The lower and upper $95 \%$ confidence bounds for the Weibull distribution in the lightly grazed pastures were 57 and $628 \mathrm{~kg} \mathrm{ha}^{-1}$, respectively and 24 and $576 \mathrm{~kg} \mathrm{ha}^{-1}$ for the heavily grazed pasture.

The normal distribution approximated $63 \%$ of the biomass in the heavily grazed pasture to be $270 \mathrm{~kg} \mathrm{ha}^{-1}$ and the lightly grazed pasture to be $347 \mathrm{~kg} \mathrm{ha}^{-1}$. The amounts represented by the data, as determined from the 63 percentile of the data, were 231 and $339 \mathrm{~kg}$ $\mathrm{ha}^{-1}$, respectively. Thus the normal distribution overestimated the amount of forage by $17 \%$ for $63 \%$ of the heavily grazed pasture area when compared to the data set, while the lightly grazed pasture biomass was overestimated by $2 \%$. On the other hand, the Weibull distribution estimated the amount of biomass for $63 \%$ of the pasture area as less than $249 \mathrm{~kg} \mathrm{ha}^{-1}$ in the heavily grazed pasture and $337 \mathrm{~kg} \mathrm{ha}^{-1}$ in the lightly grazed pasture-an overestimate of $8 \%$ and an underestimate of less than $1 \%$, respectively. The normal distribution also underestimated the lower and upper $95 \%$ confidence bounds for both the lightly and heavily grazed pasture: 8 and $589 \mathrm{~kg} \mathrm{ha}^{-1}$ and -77 and $529 \mathrm{~kg} \mathrm{ha}^{-1}$, respectively.

The Weibull distribution compared to the normal provided a closer approximation of the amount of forage, as observed by the actual frequency distribution, for both levels of grazing. In addition, the Weibull distribution will never have a negative value for amount of forage, but the normal might give a negative value when confidence intervals are used about the mean as demonstrated in the example above. That is, based on the assumption of normality at a given percentile, there is the possibility that the value for plant height or biomass could be negative.

\section{Conclusions}

Results of this study indicated that the Weibull distribution may be more appropriate than the normal to describe plant heights and forage biomass on a shortgrass steppe. The height and biomass data suggest that patterns are caused in part by grazing intensity and as a result, the Weibull distribution is useful for interpreting the effects of grazing on blue grama/buffalograss mixtures.

The results also revealed limitations of the normal distribution in describing data distributions for plant height and biomass. Because of these limitations, the Weibull distribution is then suggested as an alternative to the normal distribution. This recommendation is based on the fact that the Weibull fit all data for each level of grazing and each date, while the normal was very limited in describing the data. This clearly demonstrated the inherent flexibility of the Weibull to account for normal distributions as well as for skewness in data. Further studies are needed to contrast sodforming grasses, which tend to produce close to uniform amounts of 
biomass, with bunchgrasses on a per unit area basis.

\section{Literature Cited}

Anderson, E.W., and W.F. Currier. 1973. Evaluating zones of utilization. J. Range Manage. 26:87-91.

Bailey, R.L., and T.R. Dell. 1973. Quantifying diameter distributions with the Weibull function. Forest. Sci. 19:97-104.

Baker, W.L. 1989. Effects of scale and spatial heterogeneity on fire-interval distributions. Can. J. Forest. Res. 19:700-706.

Bridges, D.C., H.I. Win, P.J. Sharpe, and J.M. Chandler. 1989. Modeling distributions of crop and weed seed germination time. Weed Sci. 37:724-729.

Greenwood, J.A., J.M. Landwehr, N.C. Matalas, and J.R. Wallis. 1979. Probability weighted moments: Definition and relation to parameters of several distributions expressible in inverse form. Water Resource Res. 15:1049-1054.

Grender, J.M., T.R. Dell, and R.M. Reich. 1990. Theory and derivation for Weibull parameter probability weighted moment estimators. Res. Pap. SO-260. New Orleans, Louisiana: USDA, Forest Serv., Southern Forest Exp. Sta.

Holechek, J.L., R.D. Pieper, and C.H. Herbel. 1989. Range management. Prentice Hall, N.J.

Hollander, M., and D.A. Wolfe. 1973. Non-parametric statistical methods. John Wiley and Sons, N.Y.

Jameson, D.A., R.D. Bement, C. Copeland, J. Crab, W. Franklin, F. Smith, D. Bartos, W. Klein, R. Ryder, R. Hansen, G. Bertolin, and R. Engel. 1969. General description of the Pawnee Site. U.S. IBP Tech. Rep. 1., Natur. Res. Ecol. Lab., Fort Collins, Colo.
Johnson, N.L., and S. Kotz. 1971. Continuous univariate distributions. Vol. 1. John Wiley and Sons, N.Y.

Milchunas, D.G., W.K. Lauenroth, P.L. Chapman, and M.K. Kazempour. 1990. Community attributes along a perturbation gradient in a shortgrass steppe. J. Veg. Sci. 1:375-384.

Milchunas, D.G., W.K. Lauenroth, P.L. Chapman, and M.K. Kazempour. 1989. Effects of grazing, topography, and precipitation on the structure of a semiarid grassland. Vegetatio 80:11-23.

Reich, R.M., T.R. Dell, and J.M. Grender. 1991. Experience with Probability Weighted Moments for Weibull parameters estimation in diameter distributions. Forest. Sci. (submitted).

Shiyomi, M. 1985. Spatial patterning of grazing pasture plant biomass and its prediction. J. Japan. Grassl. Sci. 31:1-13.

Shiyomi, M., T. Tsuyoshi, and S. Takahsashi. 1983. A spatial pattern model fo plant biomass in grazing pasture I. J. Japan Grassl. Sci. 28:373-382.

Shiyomi, M., T. Tsuyoshi, and S. Takahashi. 1984. A spatial pattern model of plant biomass in grazing pasture II. J. Japan Grassl. Sci. 30:43-51.

Stephens, M.A. 1974. EDF statistics for goodness of fit and some comparisons. J. Amer. Stat. Assoc. 69:730-737.

Wang, C.C., and K.H. Lin. 1986. Fitting method of Weibull equation: Application of optimum seeding method to the fitting of the progressive curve of plant disease. J. of So. China Agr. Univ. 7:17-20.

Williams, R.E. 1954. Modern methods of getting uniform use of range. J. Range Manage. 7:77-81. 